\title{
EDUCAÇÃO PARA O EMPODERAMENTO: UMA AGENDA PARA A IGUALDADE DE GÊNERO NA POLÍTICA EM ABAETETUBA-PARÁ ${ }^{1}$
}

\author{
Igora Irma Santos DACIO ${ }^{2}$ \\ Campus Universitário de Abaetetuba/UFPA \\ igdacio15@gmail.com
}

Resumo: Este trabalho trata da trajetória feminina na política na cidade de Abaetetuba-PA. Tem como objetivo analisar a atuação da mulher no campo político, e apontar a educação como forma de empoderamento, tanto para ampliar a inserção feminina na carreira política quanto para a igualdade de gênero na política. $O$ referencial teórico utilizado transita por autores/as que promovem a discussão sobre os Estudos de Gênero, em que contei com Louro (1997), Beauvoir (1970), Alves \& Pitanguy (1985), Bourdieu (2002), Badinter (1991), Perrot (1998) e Facio (2006). P|ara a discussão teórica acerca da presença feminina no campo político, acionei Álvares (2014), Freire (1987), Silva (1999); e Silva, Ramos \& Rodrigues (2013) para o debate sobre educação e currículo. Acionando os pressupostos da pesquisa qualitativa, realizei entrevistas com 4 mulheres que ocuparam-ocupam cargo político na cidade. Os resultados apontam que a participação feminina na política em Abaetetuba é tímida pela falta de fiscalização dos partidos que não cumprem a Lei de Cotas, pela ainda forte cultura de gênero que mantém a Mulher no espaço privado, e pela limitação na formação escolar que não forma as mulheres para o exercício da cidadania plena. Concluo que o empoderamento é uma estratégia de formação e de ação possível por meio do currículo escolar, na medida em que este implemente conhecimentos sobre as lutas e resistências das mulheres, para que estas possam reconhecer a importância de assumir seu lugar nos espaços de decisões políticas e lutar pela igualdade de gênero na sociedade.

Palavras-chave: Política. Empoderamento feminino. Educação.

\begin{abstract}
This work is about the female political trajectory in the city of Abaetetuba-PA; the objective is to analyze the performance of women in the political field and to show education as a way of empowerment both to expand women's insertion in the political career and to gender equality in politics. The theoretical reference contains multiple authors that promotes the discussion about Gender Studies, where I counted with Beauvoir (1970), Alves \& Pitanguy (1985), Bourdieu (2002), Badinter (1991), Perrot (1998) and Facio (2006); for the theoretical discussion about the feminine presence in the political field, I brought Álvares (2014), Freire (1987), Silva (1999) and Silva, Ramos \& Rodrigues (2013) for the debate on education and curriculum. I have used the qualitative research assumptions, I conducted interviews with 4 women who hold-held political office in the city. The results indicate that female participation in politics in Abaetetuba is timid due to the lack of supervision by political parties that do not comply with the Quotas Law, by the still strong gender culture that keeps Women in private space, and by the limitation in school education that does not educate Women for the exercise of full citizenship. I conclude that empowerment is a possible training and action strategy through the school curriculum as it implements knowledge about women's struggles and resistance so that they can recognize the importance of taking their place in political decision-making spaces and fight for gender equality in society.
\end{abstract}

Keywords: Politics. Female Empowerment. Education.

\footnotetext{
${ }^{1}$ Parte deste artigo foi apresentado como trabalho final do curso de Especialização Educação em Direitos Humanos $e$ Diversidade/ICJ/UFPA.

${ }^{2}$ Pedagoga, Especialista em Educação em Direitos Humanos e Diversidade/ICJ/ UFPA. Integrante do Gepege - Grupo de Estudos e Pesquisas Gênero e Educação. Mestranda no Programa de Pós-Graduação em Cidades, Território e Identidades - PPGCITI/UFPA.
} 


\section{Introdução}

A desigualdade de gênero na política se constitui um grande entrave para que se alcance a democracia plena. Ainda que as mulheres sejam a maioria das eleitoras, são apenas $10 \%$ do total de parlamentares da Câmara e somente $16 \%$ das cadeiras no Senado. Deve ser ressaltado também que, dos 28 partidos que elegeram parlamentares para a Câmara dos Deputados, onze deles não possuem mulheres como representantes. Além do mais, dezesseis estados não contam com a representação feminina no Senado Federal.

Diante desses fatos, surgiu o interesse por realizar uma pesquisa acerca da desigualdade de gênero existente no cenário político na cidade de Abaetetuba, Estado do Pará, marcado pela presença masculina. No caso de Abaetetuba, contamos apenas com 3 representantes, uma na Prefeitura e duas na Câmara Municipal. Com isso, surgiu o seguinte questionamento: De que forma a educação pode contribuir para o empoderamento feminino e aumento da participação feminina na política? Com o objetivo de responder a essa pergunta, serão analisadas as trajetórias políticas de quatro mulheres em Abaetetuba, conforme as seguintes orientações: 1) Verificar quais os desafios encontrados pelas Mulheres para o exercício de cargos políticos; 2) Observar quais fatores contribuem para o impedimento da consolidação de uma democracia paritária em Abaetetuba-PA; 3) Discutir o papel da educação para o empoderamento feminino e para a ampliação de seu espaço na esfera política.

Para alcançar os objetivos propostos, utilizarei os pressupostos da pesquisa qualitativa, que "[...] implica uma partilha densa com pessoas, fatos e locais que constituem objetos de pesquisa, para extrair desse convívio os significados visíveis e latentes que somente são perceptíveis a uma atenção sensível.” (CHIZZOTTI, 2003, p. 2). A coleta de dados se deu por meio de entrevistas, que me possibilitaram obter a informação necessária para a análise do problema proposto, por meio de perguntas pré-estabelecidas. Em um primeiro momento, entrei em contato com as entrevistadas, que se disponibilizaram a ceder as entrevistas em seus locais de trabalho, com exceção de uma que já não se encontra mais em exercício político. Após as entrevistas, selecionei trechos destas que contribuíram para a análise subsequente.

O trabalho está organizado da seguinte maneira: iniciarei falando sobre o município de Abaetetuba, sobre as mulheres que já passaram pela Prefeitura, sendo uma como prefeita e outra 
vice, e pela Câmara dos Vereadores, apresentando suas respectivas trajetórias políticas; em seguida, discutirei os desafios de conciliar a tripla jornada de trabalho e os desafios para termos mais mulheres atuando no campo político; encerrarei com o debate sobre a educação para o empoderamento feminino.

\section{Abaetetuba e a participação feminina na Política: breve histórico}

Abaetetuba, que, no Tupi-Guarani, significa "Terra de Homens Fortes e Valentes", pertence ao Estado do Pará e encontra-se localizada a 121,8 km da capital, Belém. O município se desenvolveu às margens do Rio Maratauíra, afluente do Rio Tocantins. Sua população é estimada em 150.431 habitantes (IBGE, 2015). O município é o $6^{\circ}$ maior do interior do Pará, possuindo importante polo comercial na região do Baixo Tocantins. O município é formado pelos bairros: Centro, São Lourenço, Algodoal, Santa Rosa, São Sebastião, Multirão, Aviação, Angélica, Cafezal, São João, Cristo Redentor, Francilândia, Santa Clara, São José, Castanhal e Bosque.

Pérola do Tocantins, Terra da Cachaça, Cidade das bicicletas, Medellín Nacional, Cidade do brinquedo de Miriti numa síntese de elementos conflitivos e agregadores que apontam ora para uma cidade encantada pela cultura, ora desfigurada pelo imaginário urbano, orientados em torno do tema do progresso (GOMES, 2013, p. 28).

Abaetetuba, exposta poeticamente e também de forma realista por Gomes (2013), ganhou fama como a pérola do Tocantins, por ser a cidade mais desenvolvida do Baixo Tocantins à época da composição do hino do município. Outras alcunhas devem-se à produção da cachaça nos engenhos presentes em suas ilhas, pelo grande número das bicicletas no município e pela produção artesanal dos brinquedos que renderam ao município o título de Capital Mundial dos Brinquedos de Miriti. Recentemente, foi tratada como Medellín Nacional pela revista Veja (Setembro-2009), por ser uma rota internacional do tráfico de drogas.

O município já teve 17 legislaturas em períodos de mandatos variados. A primeira legislatura do município foi em 7 de janeiro de 1881. Entretanto, a primeira mulher foi eleita somente em 1982, mais de 100 anos depois, para a Câmara Municipal, sendo a ex-vereadora Joserlina Maués, do Partido do Movimento Democrático Brasileiro (PMDB), do mesmo partido do prefeito e governador da época, João Bitencourt e Jader Barbalho, respectivamente. Até o momento, passaram pela Câmara apenas quatro mulheres: Joserlina Maués (PMDB), Joana 
Conceição do Partido dos Trabalhadores (PT), Andrea Pacheco do Partido Progressista (PP) e Edileuza Muniz (PT), as duas últimas ainda se encontram cumprindo mandato.

Joserlina Maués foi a primeira vereadora no município de Abaetetuba (1982-1996) e a segunda vereadora eleita foi Joana Conceição (1988-1992). Andrea Pacheco foi eleita em 2012 e Edileuza Muniz em 2008; ambas encontram-se no fim dos seus mandatos; sendo que Edileuza finda seu segundo mandato e caminha rumo ao terceiro. No poder executivo, atualmente, encontra-se no centro de decisões políticas a prefeita Francinete Carvalho, eleita pelo Partido da Social Democracia Brasileira (PSDB), em 2008, e já findando seu segundo mandato. O município também contou com a participação feminina de Antônia Botelho do Partido Socialista Brasileiro (PSB), como vice-prefeita de Luiz Lopes (PT), de 2004 a 2008. Inferi, de acordo com essas informações, que Abaetetuba não se constitui em exceção, visto que também é pequena a parcela feminina atuando politicamente em outras cidades brasileiras.

Essa é uma situação de desigualdade histórica que, para Badinter (1991), é o resultado do que as circunstâncias, os governos e as leis fazem. Para que as Mulheres se reconheçam enquanto seres condicionados e excluídos durante anos dos locais de decisões políticas, é preciso que sejam empreendidas ações afirmativas, como o intuito de ampliar a presença feminina e superar as visões preconceituosas que acreditam que lugar de mulher é no lar, se possível distante de locais em que possam ameaçar a hegemonia masculina.

Sobre isso, Beauvoir (1970, p.18) ressalta que “As mulheres, em seu conjunto, são hoje inferiores aos homens, isto é, sua situação oferece-lhes possibilidades menores: o problema consiste em saber se esse estado de coisas deve perpetuar-se.”. E, em caso negativo, há que se lutar para que essa situação de desigualdade e hierarquização entre os gêneros (pois o homem ainda é visto como superior) seja questionada e suplantada, por meio da política e, principalmente, por meio de uma educação para a política.

\section{A Trajetória política das abaetetubenses no exercício de Cargos Políticos}

A partir do cenário apresentado acima, serviram como interlocutoras deste trabalho: a prefeita Francinete Carvalho, a ex-vereadora Joserlina Maués, primeira vereadora do município, e as vereadoras Andréa Pacheco e Edileuza Muniz, ambas atualmente em exercício. Das 4 
entrevistadas, duas se consideram brancas, uma negra e outra não identificou sua cor de pele. Todas as entrevistadas possuem nível superior, com graduações em Psicologia, Pedagogia e Educação no Campo.

A trajetória política das interlocutoras variaram em termos de origem, pois aconteceram nos movimentos sociais, nos movimentos estudantis, como voluntárias em instituições religiosas, como a Pastoral do Menor, a Pastoral da Juventude, na militância nas Comunidades Eclesiais de Base (CEBS) e no Sindicato dos Trabalhadores Rurais.

Compreende-se que a participação nas comunidades tem se constituído em importante mecanismo de conscientização e politização de moradores e suas associações, sendo, por meio de suas reinvindicações, que estes acabam lançando seus próprios candidatos, para que possam defender seus interesses. Para Álvares (2014), o movimento comunitário tornou-se "um movimento político, priorizando as causas sociais, considerando que as lutas específicas devem se integrar às lutas políticas. Papel avançado de fortificação da ação, contribuindo para a emancipação social.” (p. 2265).

Sobre a preparação para o desempenho de cargo político, três das quatro entrevistadas declararam que este se deu por meio da escola, da família, dos movimentos estudantis na universidade, e dos sindicatos. Já a entrevistada Joserlina Maués (65 anos, entrevistada em 05/07/2016) afirmou que não houve uma preparação propriamente dita, mas a experiência foi fundamental para o exercício do cargo.

Durante as entrevistas, houve um direcionamento para a compreensão do papel da família na impulsão das carreiras políticas, isto é, nas relações familiares que direcionaram as carreiras com base na herança econômica e/ou política sediada no município. Francinete Carvalho (47 anos, entrevistada em 04/07/2016) citou seu pai; Joserlina Maués (65 anos, entrevistada em 05/07/2016) indicou seu pai e seu marido; Andréa Pacheco (36 anos, entrevistada em 05/07/2016) disse que não foi influenciada por familiares; e Edileuza Muniz (50 anos, entrevistada em: 06/07/2016), informou que somente seu marido teve influência direta sobre sua vontade de ser candidata.

Apesar de Andréa Pacheco afirmar que, em seu mandato não houve ninguém na família que tenha impulsionado sua carreira, seu esposo é ex-vereador, e ela afirmou, em outro momento 
da entrevista, que recebeu seu apoio e que sofreu preconceito por conta disso, uma vez que ela era vista pela sociedade como despreparada para o cargo, já que era vista como:

[...] a menina candidata, o meu marido ia escrever meu discurso, ia comandar o meu mandato e o quanto eu tive que provar que não era nada disso, por mais que eu soubesse, a gente tem que provar a todo momento. (Andrea Pacheco).

Ainda hoje, infelizmente, há, por parte da sociedade, esta exigência, de que a mulher necessita demonstrar sua capacidade para justificar sua presença em certos espaços, principalmente nos centros de decisões políticas. O pensamento de que a mulher não foi feita para a política continua sendo fortemente nutrido, pois ignora-se o fato de que: “[...] a mulher pode exercer todas as atividades masculinas, desde que o espírito da sociedade a encoraje a isso." (BADINTER, 1991, p.20).

Por mais que as mulheres sejam maioria na sociedade e, além disso, tenham estatisticamente formação superior à masculina, elas ainda são obrigadas a justificar todas as proibições e preconceitos decorrentes de suas ações, como se elas admitissem uma culpa, inferioridade e até malignidade. Essa situação contribui para que a dominação masculina seja confirmada e as representações relativas a proibições e preconceitos sejam reproduzidas. (BOURDIEU, 2002).

É interessante observar que, por mais que a mulher se candidate, seja eleita e lute em seu mandato por maior representatividade na vida política, todas as entrevistadas citaram direta ou indiretamente a importância de pais e/ou maridos em sua trajetória política. Percebe-se que elas necessitaram da figura masculina para conseguir consolidar o seu poder diante da sociedade. Sobre essa questão, Beauvoir (1970) argumenta:

No momento em que as mulheres começam a tomar parte na elaboração do mundo, esse mundo é ainda um mundo que pertence aos homens. Eles bem o sabem, elas mal duvidam. Recusar ser o Outro, recusar a cumplicidade com o homem seria para elas renunciar a todas as vantagens que a aliança com a casta superior pode conferir-lhes. (BEAUVOIR, 1970, p. 15).

Desse modo, as mulheres utilizam dessa aliança entre gêneros como forma de obter os benefícios que ela lhe proporciona, uma vez que a sociedade contribui para essa visão 
androcêntrica $^{3}$, que necessita de uma figura firme e forte para dar-lhes segurança, sendo, no caso, essa figura a do homem. A mulher é vista como sexo frágil, que não possui afinidade ou é incapacitada para exercer tais cargos, logo só consegue eleger-se com o apoio do homem.

Assim, a inserção feminina na política ocorre, em grande parte, por meio da herança política, que, segundo Álvares (2014), é a principal fonte de recrutamento de políticos/as. A estratégia de uso da herança política fortalece as bases de poder de certos grupos políticos, por meio da hereditariedade que tem se alargado ao incluir a mulher. Desse modo, a mulher, de acordo com as limitações mantidas pela racionalidade do contexto privado para este gênero (domesticidade, maternidade), tem contribuído na linhagem política familiar.

A herança política muito tem contribuído para a formação e consolidação de carreiras políticas, na medida em que elas se constituem um importante meio para a admissão de candidatos/as. Nesse sentido, os indivíduos vindos de famílias que têm predominância na política local acabam por assumir um cargo político também, como seus antepassados. Portanto, os "projetos individuais sempre interagem com outros dentro de um campo de possibilidades. Não operam num vácuo, mas sim a partir de premissas e paradigmas culturais compartilhados por universos específicos." (VELHO, 1994, p. 46 - grifos do autor). Conclui-se que há uma relação direta entre a ideia de projetos individuais e os muitos campos de possibilidades de atuação política, influenciada pela cultura local.

\section{A tripla jornada de trabalho: ousadia de ser esposa, mãe e legisladora}

Um dos fatores que impede ou, ao menos, contribui para que a participação feminina na política não se equipare à masculina é a tripla jornada de trabalho. A mulher carrega consigo inúmeras atribuições e, dentre elas, a de ser mãe, esposa e de exercer sua função no mercado de trabalho; e acima de tudo ser mulher, que, além de desempenhar o seu papel, deve estar impecável diante da sociedade, como revelou a entrevistada Francinete Carvalho:

Esse é um grande desafio, você conciliar o cuidado da tua família e fazer política, fora uma série de situações, por exemplo, a mulher ela é mais cobrada com

\footnotetext{
${ }^{3} \mathrm{O}$ androcentrismo é centralidade, a exaltação e a valorização, das ideias e pensamentos masculinos na sociedade ocidental. 
relação a aparência. Um homem, por exemplo, um prefeito, se ele for o dia inteiro pras ilhas, ele tem mais tarde um evento, ele chega em casa, toma um banho rápido, troca de roupa e vai. A mulher é diferente, porque se for assim vão dizer: "poxa essa prefeita" e dizem "ela é relaxada, olha esse cabelo, sem pentear, sem escovar". Então a sociedade ainda cobra, ainda exige que a mulher esteja bonita, arrumada, produzida, que ela dê conta da casa, da família.

Percebi, na fala da entrevistada, que a própria sociedade contribui para que haja essa distância entre mulher e locais de decisões políticas, no sentido de exigir dela, além da competência para governar, delicadeza e elegância. E essa mesma sociedade trata com indiferença ou com pouca exigência quando esses quesitos dizem respeito ao homem.

Esse mesmo olhar é responsável por atribuir à mulher o sentimento de culpa que sente quando necessita afastar-se do lar. Analisando esse fato, Lages, Detoni \& Sarmento (2005, p. 3) afirmam que isso acontece porque a mulher continua sendo socialmente considerada como elo da família, e que, portanto, se espera que ela desenvolva esse papel, mas que também produza, isto é, além de ter o seu trabalho profissional, não abandone a sua missão de protetora e mantenedora social do lar.

Além da exigência da sociedade por uma legisladora perfeita, a exposição também foi citada como um dos fatores que dificultam conciliar a vida pessoal com a carreira política. Somada a essa exposição, foi citado também por Joserlina Maués o problema que o homem tem para aceitar que a mulher assuma um cargo superior ao seu. Ela mencionou, em outro momento da entrevista, que optou pela vida política por insistência de amigos e do marido. Curiosamente, este mesmo marido, que apoiou a sua candidatura, não soube lidar com o poder adquirido em decorrência do cargo como vereadora e presidente da Câmara, sendo esse um dos fatores que contribuíram para sua separação e, consequentemente, sua desistência da política.

Observei que ainda há, por parte da própria sociedade, uma forte ideologia que inferioriza a mulher, reafirma a hegemonia masculina e contribui para restringir suas potencialidades de desenvolvimento, colocando-a em posição desigual em relação ao homem. Essa mesma ideologia é perpetuada pela família, escola, religiões, meios de comunicação, espaços em que a mulher, na maioria das vezes, é vista como um ser sem autonomia para tomar decisões, sendo submissa ao homem, o que acaba criando uma hierarquia nos papéis sexuais (ALVES; PITANGUY, 1985). 
Compreendi que esse pensamento se perpetua por encontrar, na própria sociedade, um verdadeiro campo fértil para se estabelecer, encontrando condições favoráveis para se naturalizar e incorporar. É o que Bourdieu (2002, p. 25) denomina de força simbólica, que diz respeito a uma "forma de poder que se exerce sobre os corpos, diretamente, e como que por magia, sem qualquer coação física; mas essa magia só atua com o apoio de predisposições colocadas, como molas propulsoras na zona mais profunda dos corpos.".

Portanto, a sociedade acaba sendo conivente nessa relação de dominante/dominado, que contribui por excluir a mulher dos centros de decisões políticas, mesmo com a implementação de ideias e ações que reproduzem tal situação. Essa exclusão é mais severa com as mulheres, pois, como esta liga-se ao sexo, não pode ser modificada, como a idade, a nacionalidade ou o nível de riqueza, responsáveis em muitas sociedades pela conquista da cidadania (PERROT, 1998). É uma exclusão que ocorre por conta da estrutura fisiológica e "por mais longe que se remonte na história, sempre estiveram subordinadas ao homem: sua dependência não é consequência de um evento ou de uma evolução." (BEAUVOIR, 1970, pp.12-13), como no caso da escravidão de negros e de indígenas, ou justificada por guerras, nas quais o outro é subjugado e, por isso, dominado.

Por conta disso, ainda que sejam criadas cotas, ou até mesmo que haja maior incentivo à participação feminina na política por meio de campanhas da Justiça Eleitoral, há o temor ou o desinteresse de grande parte das mulheres em relação aos espaços de decisões políticas, compostos majoritariamente por homens. Essa auto-exclusão feminina pode estar relacionada aos séculos de exclusão política e social, marcadas a cada dia pela violência física e simbólica, pois "Tão logo uma mulher toma a palavra, todos se preparam para se aproveitar de suas dificuldades. Sua voz, seus gestos, seu look, todo o seu corpo é objeto de um exame em que predominam o irônico e o vulgar." (PERROT, 1998, p. 129). Por meio de situações que a cerceiam, aprisionam e imobilizam, muitas mulheres se sentem despreparadas para assumir um cargo na política. Diante de todas as dificuldades que a impedem de chegar até lá, muitas, quando chegam, sentem o peso da intimidação nesses lugares de maioria masculina. Há a necessidade de implemento de ações afirmativas e educativas que instituam uma estrutura adequada que empodere as mulheres e as prepare para o exercício dos cargos políticos. 


\section{Desafios para a consolidação de uma democracia paritária em Abaetetuba}

Notei que se constitui um grande desafio, de acordo com a entrevistada Andréa Pacheco, desvincular a vida pessoal da vida política. Sobre essa questão, a interlocutora afirmou que ser mãe e esposa torna ainda mais difícil essa separação. Afirma a entrevistada:

Eu sou mãe, tenho 2 filhos, o meu marido é envolvido, então a gente não tem como não levar os conflitos, as discussões, os desentendimentos para o convívio familiar.

Diante disso, pude compreender que, sobre a mulher, ainda recai o desafio de articular as inúmeras atribuições, inclusive as domésticas, que são consideradas de natureza feminina, já que ela é considerada "benéfica para a sociedade inteira” (PERROT, 1998, p. 7).

Um segundo desafio observado foi a inexistência de iniciativas que visassem ampliar a participação feminina na política, em que percebi, por meio das respostas das interlocutoras, que, apesar da afirmação de que, em seus mandatos, foram criadas políticas para ampliar a participação feminina na política, não é o que foi observado na prática, visto que "não houve nenhum testemunho de que as metas das políticas públicas para o crescimento do número de mulheres constituíssem um dos parâmetros de sua carreira nos espaços do poder local.” (ÁLVARES, 2014, p. 2283). O que observei, em grande parte, por meio das respostas dadas, é que elas buscavam mascarar a ausência de políticas públicas efetivas que visassem realmente trazer mais mulheres para o campo político.

Outro problema, também citado durante as entrevistas, foi o do preenchimento de vagas para o cumprimento da porcentagem estabelecida em Lei, que, segundo Andréa Pacheco, “Às vezes é colocado o nome da mulher nos partidos pra cumprir essa porcentagem, mas ela não participa, ela não se envolve, ela não discute, é usado o nome só pra cumprir uma tabela". A falta de punição quanto aos partidos que utilizam de candidaturas apenas para compor as cotas partidárias estabelecidas pela Lei 12.034/200, constitui-se num grande entrave para a consolidação de uma democracia paritária, não somente em nível local, mas nacional também.

Sobre quais as medidas necessárias para que se tenha mais mulheres exercendo cargos políticos, foi ressaltado pelas entrevistadas o estabelecimento de um número mínimo de cotas, bem como o estabelecimento de uma educação libertadora, tanto na família quanto na escola, como 
citado pela prefeita Francinete Carvalho, que ensinará sua filha a ser responsável com sua liberdade, que, para ela, "É uma medida que deve começar nas famílias e nas escolas. Ensinar em casa sobre a divisão de tarefas. A escola tem esse papel de não perpetuar uma educação sexista”. A importância da educação relaciona-se à superação da condição de desigualdade histórica em que as mulheres se encontram ou até mesmo na condenação a permanecer na exclusão sem o direito do exercício pleno da cidadania.

É bem evidente que os homens e as mulheres têm a mesma natureza e a mesma constituição (...): assim, a fraqueza de nossa constituição e de nossos órgãos pertence certamente à nossa educação, e é uma consequência da condição que nos destinaram na sociedade. (BADINTER, 1991, p. 138).

Nesse sentido, uma educação libertadora diz respeito à mudança nos comportamentos que tendem a naturalizar a hegemonia masculina. Além do desafio de uma revolução sexual, que mudaria o pensamento e as relações enraizadas pela injustiça e opressão sobre a mulher, seria necessário também enfrentar os aspectos sociais que contribuem para situá-la em lugar inferior, visto que não basta a criação de leis quando há um comportamento que a própria sociedade naturaliza e que colabora com a exclusão feminina. Diante disso, Álvares pontua os seguintes desafios para a ruptura destes obstáculos:

Romper com a dimensão cultural e ideológica ainda forte que mantém uma auto exclusão das mulheres aos cargos de decisão política; avaliar quais os recursos do sistema eleitoral brasileiro (as dimensões de demanda partidárias, o sistema proporcional de lista aberta) refreiam as candidaturas e são inoperantes para a eleição das mulheres; avaliar a decisão do voto do eleitorado para a candidatura das mulheres e ver onde está o nó do reconhecimento do valor das mulheres para um assento parlamentar. (2014, p. 2283).

Aliada a uma educação libertadora, seria necessário também, de acordo com as entrevistadas, a conscientização da capacidade da mulher em assumir cargos políticos. Essa conscientização diz respeito ao empoderamento feminino, para que, por meio deste, as mulheres fortaleçam sua atuação e participação não somente na política, mas no mercado de trabalho e nos demais espaços da sociedade. A partir do momento em que a mulher reconhece sua importância, ela é capaz de promover mudanças e lutar pela igualdade de gênero. 
Sobre isso, a ONU Mulheres ${ }^{4}$ estabeleceu os sete Princípios de Empoderamento das Mulheres, que são: 1. Estabelecer liderança corporativa sensível à igualdade de gênero, no mais alto nível; 2. Tratar todas as mulheres e homens de forma justa no trabalho, respeitando e apoiando os direitos humanos e a não-discriminação; 3. Garantir a saúde, segurança e bem-estar de todas as mulheres e homens que trabalham na empresa; 4. Promover educação, capacitação e desenvolvimento profissional para as mulheres; 5. Apoiar empreendedorismo de mulheres e promover políticas de empoderamento das mulheres através das cadeias de suprimentos e marketing; 6. Promover a igualdade de gênero através de iniciativas voltadas à comunidade e ao ativismo social; 7. Medir, documentar e publicar os progressos da empresa na promoção da igualdade de gênero 5 .

Esses princípios defendidos pela ONU Mulheres são voltados para os negócios e a comunidade empresarial, mas estão intimamente relacionados à conquista de poder feminino, de seu protagonismo e do fortalecimento de iniciativas de espírito de liderança em ambientes de predominância masculina. Dentre estes, os espaços de decisões políticas precisam ser considerados, pois ainda é um lugar em que as mulheres timidamente vêm conquistando vez e voz.

\section{Educação como ferramenta para o empoderamento político das Mulheres}

A paridade de gênero na política está diretamente ligada à democracia, na qual a soberania é exercida pelos cidadãos-cidadãs. Sendo assim, estes necessitam ter seus direitos garantidos, tais como o direito à educação, à vida, à liberdade e à igualdade, defendidos na Declaração Universal dos Direitos Humanos (DUDH), cujo destaque se dá ao Artigo I: “Todos os seres humanos nascem livres e iguais em dignidade e direitos. São dotados de razão e consciência e devem agir em relação uns aos outros com espírito de fraternidade". Porém, ainda que institucionalizado, é válido questionar se houve/há a criação de oportunidades para que seja garantida a igualdade entre os gêneros.

Esse mesmo questionamento pode ser feito ao Artigo XXI, inciso 1, que destaca: “Todo ser humano tem o direito de fazer parte no governo de seu país diretamente ou por intermédio de

\footnotetext{
${ }^{4}$ ONU - Organização das Nações Unidas, criada em1945 com o objetivo de promover a cooperação entre as nações.

${ }^{5}$ Disponível em: http://www.onumulheres.org.br/referencias/principios-de-empoderamento-das-mulheres/ 
representantes livremente escolhidos”. Uma vez reconhecida a equidade para fazer parte do governo, são criadas condições que visem à paridade nos órgãos de decisões políticas? Não há dúvidas da grandeza e nobreza dos ideais defendidos pela DUDH, porém, quase 70 anos após sua criação, mesmo que inspirando constituições pelo mundo, está longe de ser exercida.

Um dos entraves para a conquista da liberdade encontra-se justamente na deficiência da educação que deveria ser oferecida para a formação do cidadão/cidadã crítico/a, autônomo/a e participativo/a na sociedade. Contudo, nas escolas, é ofertada somente uma educação intelectual permeada por conteúdos eruditos, valorizando uma cultura que foge a realidade de muitos/as estudantes, enquanto que as diversidades culturais, étnicas, religiosas e de gênero são postas de lado. Sendo esta exclusão grande responsável no comprometimento da formação do/a cidadão/ã, ela mesma contribui também para a exclusão feminina do campo político.

Por conta dessa exclusão, um dos princípios estabelecidos pela ONU Mulheres diz respeito à promoção da educação visando ao empoderamento feminino. Empoderamento este que tem sua origem na língua inglesa, com a palavra empowerment, e que significa dar poder, fortalecer. Na língua portuguesa, esta palavra foi empregada por Paulo Freire, que utiliza a expressão em seu sentido transformador, de libertação do oprimido ${ }^{6}$; em sua obra Pedagogia do Oprimido ele afirma:

O importante, por isto mesmo, é que a luta dos oprimidos se faça para superar a contradição em que se acham. Que esta superação seja o surgimento do homem novo - não mais opressor, não mais oprimido, mas homem libertando-se. Precisamente porque, se sua luta é no sentido de fazer-se Homem, que estavam sendo proibidos de ser, não o conseguirão se apenas invertem as termos da contradição. Isto é, se apenas mudam de lugar, nos polos da contradição. (FREIRE, 1987, p. 24).

Nesse sentido, pensar o empoderamento das mulheres, a libertação do estado de opressão em que se encontram, atravessa necessariamente o ato de refletir o papel da educação em suas vidas. Uma vez que a prática educativa prime por uma educação libertadora, os sujeitos poderão adquirir consciência de si e de outros indivíduos, diluindo o silenciamento das vozes femininas. A educação libertadora não cerceará as liberdades inerentes ao ser humano, independente de gênero, classe, etnia, religião e sexualidade.

\footnotetext{
${ }^{6}$ Para saber mais: http://tupi.fisica.ufmg.br/ michel/docs/Artigos_e textos/Comportamento_organizacional/ empowerment_por_paulo_freire.pdf 
Por conta disso, faz-se necessário incluir nos currículos a história de lutas, reações, resistências e movimento de mulheres por direitos ao longo da história, a História das Mulheres "e não uma História dos Homens — afinal essa última é a História geral, a História oficial.” (LOURO, 1997, p. 50). É a história masculina que se aprende nas escolas, é o protagonismo, a grandeza e os feitos heroicos dos homens que são estudados, enquanto as mulheres ficam em segundo plano. Não se trata de inverter as relações entre oprimido e opressor, ou seja, elevar a história feminina em detrimento à masculina, mas valorizar igualmente a presença de homens e mulheres na história “oficial", o que requer mudanças no currículo escolar, pois,

Na medida em que reflete a epistemologia dominante, o currículo existente é também claramente masculino. Ele é a expressão da cosmovisão masculina. $\mathrm{O}$ currículo oficial valoriza a separação entre sujeito e conhecimento, o domínio e o controle, a racionalidade e a lógica, a ciência e a técnica, o individualismo e a competição. Todas essas características refletem as experiências e os interesses masculinos, desvalorizando, em troca, as estreitas conexões entre quem conhece e o que é conhecido, a importância das ligações pessoais, a intuição e o pensamento divergente, as artes e a estética, o comunitarismo e a cooperação características que estão, todas, ligadas às experiências e aos interesses das mulheres. A solução não consistiria simplesmente numa inversão, mas em construir currículos que refletisse, de forma equilibrada, tanto a experiência masculina quanto a feminina. (SILVA, 1999, p. 94).

Portanto, não se trata apenas de subverter a ordem em que os conteúdos estão divididos no currículo escolar, mas de transformá-lo para que possa refletir as experiências de ambos, e, dessa forma, desnaturalizar a "neutralidade" presente no currículo, que reforça os estereótipos e mascara a hierarquização nos papeis sexuais. O currículo é um artefato de gênero e, segundo SILVA (1999), corporifica e produz relações de gênero, portanto deixar de examiná-lo seria uma perspectiva bastante parcial e limitada deste artefato.

A partir do momento em que as mulheres se reconheçam como seres historicamente excluídos e percebam a importância do seu papel na luta por uma sociedade digna e justa, elas serão mulheres mais atuantes no campo político, e não somente nele, mas nos demais campos da sociedade. Serão mulheres empoderadas, que irão se mobilizar, terão autonomia para o questionamento e fiscalização do cumprimento das leis que são marcadamente androcêntricas, em que "os homens continuam a ocupar as posições mais importantes e são os que determinam o modo de olhar a realidade social, dando-lhe uma aparência de normalidade mesmo perante aquelas que lhe estão subordinadas." (FACIO, 2006, p. 4). 
Dessa forma, será a função da escola trabalhar no sentido de preparar Mulheres e Homens para o exercício da cidadania e da democracia, marcada pela soberania popular, em que as pessoas têm o direito de votar e serem votadas. Para tanto, é essencial e se constitui um grande desafio que, neste mesmo ambiente de ensino, se promova uma educação que tenha como objetivo a igualdade de gênero, visto que é um local marcadamente reprodutor de desigualdades, pois "É no contexto das desigualdades produzidas nas tramas de uma história que exclui os diferentes, em nome de uma identidade normativa, que se deve lutar para garantir políticas públicas de educação voltadas aos direitos humanos." (SILVA; RAMOS; RODRIGUES, 2013, p.166). Políticas públicas voltadas à valorização e respeito às diversidades: eis o caminho.

\section{Considerações Finais}

A participação feminina ainda é pequena em Abaetetuba-PA, visto que há falhas na Lei de Cotas por parte da Justiça Eleitoral, que não fiscaliza ou pune adequadamente os partidos não cumpridores de suas determinações. Além disso, as inúmeras atribuições contribuem para sobrecarregar as mulheres e afastá-las dos centros de decisões políticas. Soma-se a isso o fato de que a própria sociedade é conivente com essa exclusão, na medida em que situa a mulher em lugar inferior, exigindo que ela cumpra as atribuições ditas femininas, como a preocupação com a beleza e o lar, e esquecendo que as principais características de uma legisladora devem ser a competência, honestidade e responsabilidade para governar.

Uma das indicações da ONU Mulheres para tentar sanar o problema é a educação da mulheres para o empoderamento feminino. Desse modo, a educação é indispensável para a construção de uma sociedade justa e democrática, visto que é seu papel preparar os/as estudantes para o exercício da cidadania e democracia. Nesse sentido, ela necessita desnaturalizar as desigualdades que ela mesma reproduz em seu espaço, perpetuando relações desiguais, excluindo tudo que foge ao padrão branco, masculino, heterossexual e cristão.

A partir do momento em que as escolas se desvincularem dos padrões pré-estabelecidos e se abrirem para o diálogo e respeito às diferenças, as mulheres passarão a se reconhecer quanto seres historicamente excluídos dos locais de decisões políticas, porém compreenderão suas resistências, reconhecerão a história de luta feminina, os avanços e recuos na conquista de direitos. 
Com isso, tornar-se-ão empoderadas e poderão compreender a importância de ocupar seu lugar no espaço político e, nele, lutar a favor da igualdade entre gêneros na sociedade.

\section{Referências}

ÁLVARES, Maria Luzia Miranda. Mulher(es), história(s) e poder(es): versões da política. 2014. Anais do $\mathbf{1 8}^{\circ}$ REDOR, Recife, Pernambuco, 2014. Disponível: http://paradoxzero.com/zero/redor/wp-content/uploads/2015/04/2184-4657-1-PB.pdf. $\quad$ Acesso: 20/06/2016.

ÁLVARES, Maria Luzia Miranda. Recrutamento de candidaturas nos movimentos de mulheres: rotas de acesso aos espaços de poder na democracia brasileira. Anais do $3^{\circ}$ Encontro da ANPOCS, Caxambu, Minas $\quad$ Gerais, $2010 . \quad$ Disponível: http://www.anpocs.org/portal/index.php?option=com_docman\&task=doc_view\&gid=1580\&Item id=350. Acesso: $20 / 06 / 2016$.

ALVES, Branca Moreira; PITANGUY, Jaqueline. O que é feminismo. São Paulo: Abril Cultural/Brasiliense, 1985.

BADINTER, Elisabeth. O que é uma mulher? A. L. Thomas, Diderot, Madame D’Epinay. Rio de Janeiro: Nova Fronteira, 1991.

BEAUVOIR, Simone de. O segundo sexo: fatos e mitos. São Paulo: Difusão Europeia do Livro, 1970.

BOURDIEU, Pierre. A dominação masculina. Rio de Janeiro: Bertrand Brasil, 2002.

BRASIL, PRESIDÊNCIA DA REPÚBLICA. Lei 9.096/1995. Disponível: http://www.planalto.gov.br/ccivil_03/leis/L9096.htm. Acesso: 01/07/2016.

CHIZZOTTI, Antonio. A pesquisa qualitativa em ciências humanas e sociais: evolução e desafios. Revista Portuguesa de Educação, v. 16, n. 2, 2003, pp. 221-236.

SILVA, Tomaz Tadeu. Documentos de identidade: uma introdução às teorias do currículo. Autêntica Editora, 1999.

DECLARAÇÃO UNIVERSAL DOS DIREITOS HUMANOS. Disponível: http://www.dudh.org.br/declaracao/. Acesso: 25/06/2016.

FACIO, Alda. A partir do feminismo, vê-se um outro direito. Outras Vozes, v. 15, 2006.

FREIRE, Paulo. Pedagogia do Oprimido, 17ª . ed. Rio de Janeiro, Paz e Terra, 1987.

GOMES, J.S. Cidade da Arte: Uma Poética da Resistência nas Margens de Abaetetuba. Tese (Doutorado em Ciências Sociais). Belém: Instituto de Filosofia e Ciências Humanas/UFPA, 2013. 
LAGES, Sônia Regina Corrêa; DETONI, Carolina; SARMENTO, Sandra Carrato. O Preço da Emancipação Feminina: uma reflexão Sobre o estresse gerado pela dupla jornada de trabalho. Revista Estação Científica, edição 01, agosto de 2005, pp. 1-6.

LOURO, Guacira Lopes. Gênero, sexualidade e educação: uma perspectiva pós-estruturalista. Petrópolis: Vozes, 1997.

PERROT, Michelle. Mulheres Públicas. Tradução: Roberto Leal Ferreira. São Paulo: Fundação Editora UNESP, 1998.

SENADO FEDERAL. Procuradoria Especial da Mulher; Câmara dos Deputados, Secretaria da Mulher. Mais Mulheres na Política. 2. Ed. Brasília. 2015. Disponível: http://www2.senado.gov.br/bdsf/item/id/510155. Acesso: 30/05/2016.

SILVA, Ronan Barreto Rangel da; RAMOS, Hugo Souza Garcia; RODRIGUES, Alexsandro. Gênero e sexualidade nas escolas: leituras que nos aproximam do campo dos direitos humanos, de alunos e professores. In: Rodrigues Alexsandro, Barreto Maria Aparecida Santos Corrêa (Orgs.). Currículos, gêneros e sexualidades: experiências misturadas e compartilhadas Vitória, ES: Edufes, 2013.

VELHO, Gilberto. Projeto e metamorfose: antropologia das sociedades complexas. Rio de Janeiro: Zahar Ed., 1994. 